\title{
Tubercular Cerebellar Abscess in A 5 Years Aged Boy
}

PULAK KUMAR JANA, ${ }^{1}$ IRA DAS, ${ }^{2}$ TAPAN DAS BAIRAGYA, ${ }^{3}$ SUMIT DEB ${ }^{4}$

A 5 years aged male child was admitted in the Neurosurgery department with chief complaints of fever for 2 months, generalized tonic-clonic seizures with increased frequency for last 2 months, bed wetting and rectal incontinence for 1 months. He had operated for Meningomyelocele repair at the age of 17 days and V-P Shunt was done at age of 4 months. On examination : Higher mental function- diminished, Motor system-Bilateral Upper limbs - 4/5, Bilateral lower limbs -3/5, Sensory system - normal, Reflexes - DTR +++, Plantareqivocal, Gait - child could not sit or walk. Hb-10.2\%, WBC 13600 / cu.mm, N-68\%,L-26\%,M-2\%,E-4\%, ESR-73mm, LFTnormal, Chest Xray -normal, ECHO-normal, HIV I \&II , HbsAg, Anti HCV were negative . MRI of brain shows multiple focal rim enhancing SOL with central necrosis in the posterior fossa involving cerebellar cortex, vermis with gross perilesional oedema and mass effect. Largest SOL measures $6.1 \times 4.7 \times 3.4 \mathrm{~cm}$ suggesting multiple cerebellar abscess (fig 1).

Midline suboccipital craniectomy and near total removal of left sided cerebellar sol done under GA. Histopathology of tissue showed multiple epithelioid granuloma with necrosis with Langhans giant cell suggesting tubercular etiology (fig 2). He was given ATD,CAT I along with anticonvulsant drugs (valproic acid) . After given ATD his symptoms was rapidly improved. MRI of brain after 5 months showed reduction in size of lesions with thinning of wall of the lesions with reduced mass effect, indicative of gradual improvement (fig 3).

1. Associate Professor, Department of Chest Medicine, Institute of Post Graduate Medical Education \& Research, Kolkata; Email-doctorjana_23@yahoo.com

2. Medical Officer, Department of Paediatric Medicine Medical College, Kolkata

3. Assistant Professor, Dept. of Chest Medicine, North Bengal Medical College. Darjeeling, West Bengal

4. Professor, Department of Neurosurgery, Bangur Institute Of Neurosciences,

Correspondence : Dr. Pulak Kumar Jana,Deeshari Comfort, Flat -1/1A 732 Sreenagar West, Kolkata-700094;Near Mangalik Bhavan, New Garia Housing Coperative; West Bengal , India,Emaildoctorjana_23@yahoo.com

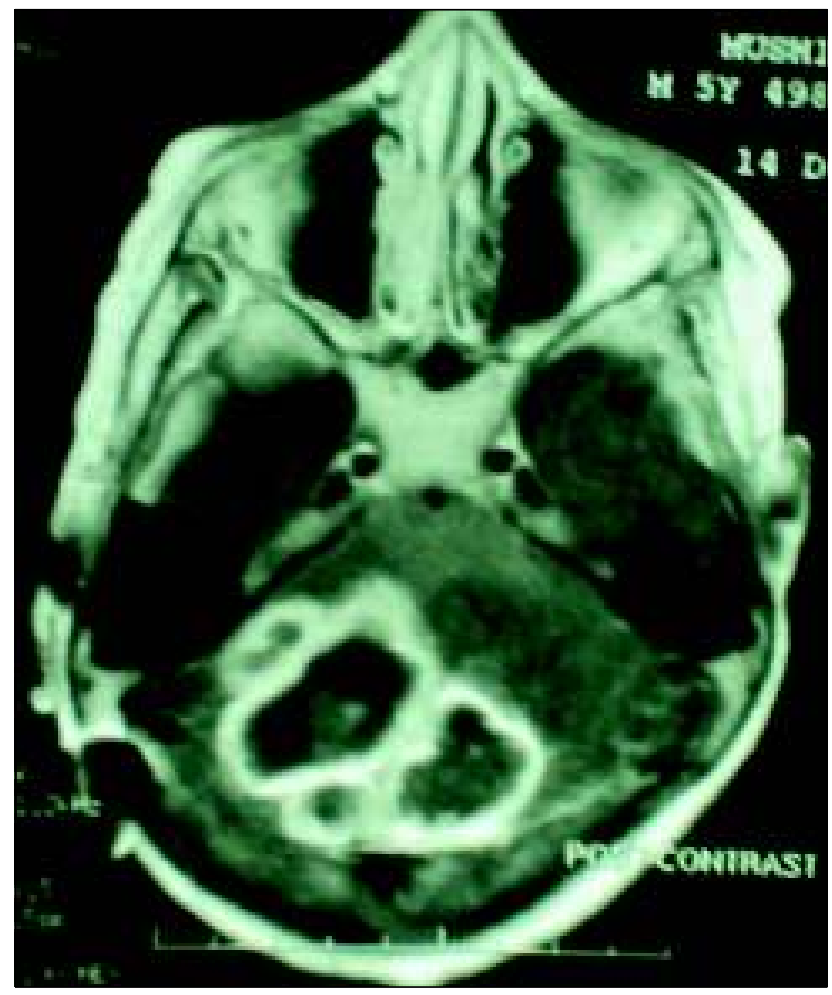

Fig.-1: MRI of brain shows multiple focal rim enhancing SOL with central necrosis in the posterior fossa involving cerebellar cortex, vermis with gross perilesional oedema and mass effect.

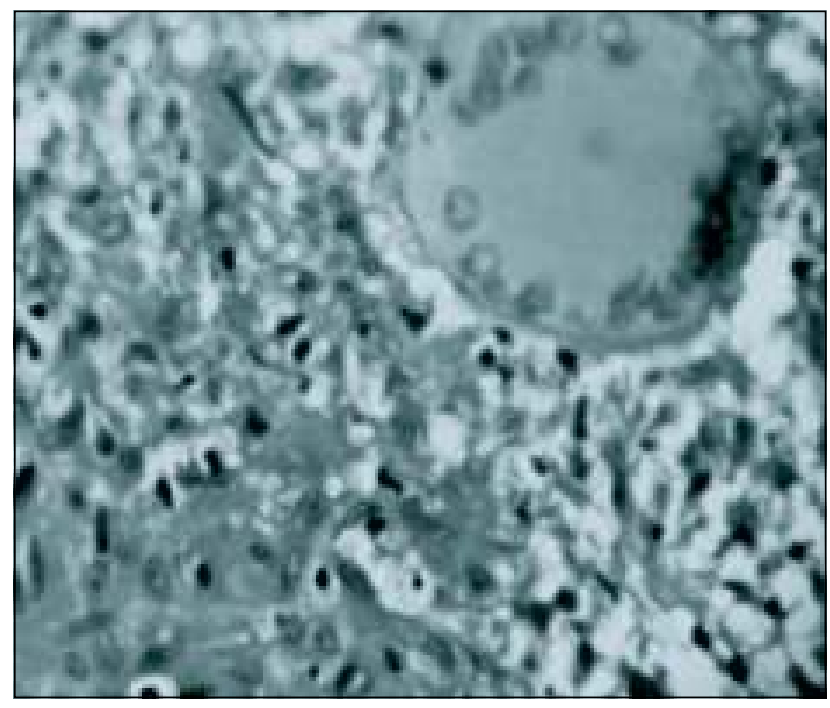

Fig.-2: Histopathology of tissue showed multiple epithelioid granuloma with necrosis with Langhans giant cell. 


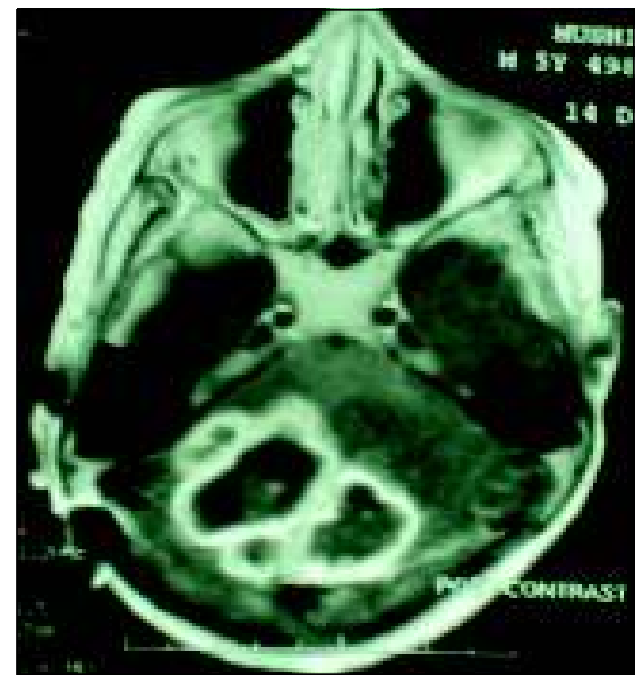

Fig.-3: MRI of brain after 5 months showed reduction in size of lesions with thinning of wall of the lesions with reduced mass effect, indicative of gradual improvement.
Tubercular abscess of brain are very uncommon and that too cerebellar abscess are very rare. ${ }^{1}$ The criteria for diagnosis include pus in the brain, bacteriological proof or histological confirmation of abscess. ${ }^{1}$ Gazzaz et al reported a case of cerebellar abscess in 2000, which was improved with surgical management and ATD. ${ }^{2}$ Though very uncommon tubercular etiology should be kept in mind along with other infectious causes of cerebellar abscess.

\section{Conflict of Interest: none}

\section{References:}

1. Wanjari K, Baradkar VP, Nataraj G, Kumar S. A rare case of tubercular cerebellar abscess. Indian J Med Microbiol 2009; $27: 363-5$

2. Gazzaz M, BonyaaKoub FA, Elkhamlichi A. Tuberculous cerebellar abscess. Acta Neurol Belg 2000; 100: 146-7 